\title{
KUALITAS JASA DAN KEPUASAN MAHASISWA PERGURUAN TINGGI SWASTA DI MALANG
}

\author{
Yayuk Sri Rahayu \\ Fakultas Ekonomi Universitas Islam Negeri (UIN) Malang \\ J1. Gajayana No. 50, Telepon (0341) 558881, Fax. (0341) 558881, \\ E-mail: feuinmlg@yahoo.co.id
}

\begin{abstract}
In globalization era, the company must have the ability to satisfy their customer to be the winner of business competitiosince customer satisfaction depends on product or service quality. The purpose of this research is to find student's assessment about service quality that was given by private universities in Malang and what kind of service quality attributes which has less performance based on student expectation. This research used purposive and accidental sampling and analysis instrument is Importance-Performance Analysis. The results show, first, level of received service quality is still under level of student expectation so they are unsatisfied second, there are four attributes which has less performance than student expectation that are the accuration of lecturer assessment, the willingness of lecturer and staff to listen and receive suggestion from students, meeting lecturer easily, and lecturer and staff serve students well. Therefore, based on this result, private universities in Malang have to make this four attributes as a major priority in continous improvement of quality program to win competition.
\end{abstract}

key words : service quality, satisfaction, competition.

Penerapan manajemen kualitas dalam industri jasa menjadi kebutuhan pokok karena kualitas jasa memberikan kontribusi pada kepuasan palanggan, pangsa pasar, dan profitabilitas. Greising (dalam Sabihaini, 2002) menyatakan bahwa hubungan antara kualitas jasa dengan profitabilitas bersifat tidak langsung yaitu melalui loyalitas pelanggan yang akan tercapai apabila pelanggan merasa puas atas kualitas jasa yang diterima. Parasuraman, Zeithaml dan Berry (1988) mengungkapkan perkembangan teknik untuk mengukur kualitas jasa. Penelitian ini mengambil sampel sebanyak 200 responden pada empat jenis industri yaitu bank, perusahaan kartu kredit, perusahaan pemeliharaan, dan perusahaan telpon. Hasil dari penelitian ini yaitu menemukan lima dimensi kualitas jasa yang terdiri dari Tangibles, Reliability, Responsiveness, Assurance, dan Empathy. 
Perguruan tinggi sebagai lembaga yang bergerak di bidang jasa harus mampu memenuhi kebutuhan dan memberikan kepuasan kepada mahasiswa sebagai konsumen. Hal ini diperlukan untuk dapat memenangkan persaingan dengan perguruan tinggi lain dan menuntut adanya komitmen untuk memuaskan pelanggan yang salah satunya dengan perbaikan mutu secara berkesinambungan. Gejala konsumerisme dapat timbul pada lembaga perguruan tinggi yang memiliki kelemahan-kelemahan seperti system pekuliahan, kualifikasi dosen, tugas bimbingan studi, fasilitas perpustakaan, laboratorium, dan sebagainya. Kondisi di atas tentu tidak berlaku umum karena banyak pula perguruan tinggi yang telah membina segi akademik dan edukatif secara baik dengan segala perlengkapan teknologi modern dan tenaga pengajar yang berkualifikasi baik.

Selama ini penilaian kualitas jasa perguruan tinggi lebih menekankan pada penilaian yang dilakukan oleh pihak lain (misalnya badan akreditasi nasional), padahal titik sentral pengelolaan perguruan tinggi adalah mahasiswa sebagai pelanggan utama. Oleh karena itu sangat penting bagi pengelola PTS untuk mendapatkan umpan balik (feedback) dari mahasiswa seperti yang disampaikan oleh Kotler (2000) bahwa kualitas harus dimulai dan berakhir pada pelanggan. Handriana (1998) melakukan penelitian tentang perbedaan harapan kualitas jasa pada pendidikan tinggi di Surabaya. Fokus penelitiannya adalah perbedaan persepsi harapan kualitas pelayanan antara mahasiswa dan dosen dengan menggunakan tiga dimensi kualitas pelayanan yaitu respek terhadap mahasiswa, pengetahuan dosen, dan lingkungan fisik perguruan tinggi. Hasil dari penelitian ini menunjukkan : 1. Adanya gap antara harapan kualitas jasa pendidikan menurut persepsi mahasiswa dan dosen, 2. Harapan terbesar mahasiswa adalah fasilitas kampus, 3. Mahasiswa PTN maupun PTS mempunyai harapan kualitas jasa pendidikan yang sama dalam ketiga dimensi tersebut.

Menurut Direktori PTS yang diterbitkan oleh KOPERTIS Wilayah VII Jawa Timur tahun 2003, di kota Malang terdapat 42 PTS yang terdiri dari 10 universitas, 24 sekolah tinggi, 4 akademi, dan 4 institut. Penelitian ini menggunakan dimensi kualitas jasa yang dikembangkan oleh Parasuraman, et.all (1988) yang terdiri dari :

1. Tangibles atau bukti fisik

2. Reliability atau keandalan

3. Responsiveness atau ketanggapan

4. Assurance atau jaminan

5. Empathy atau empati 
Berdasarkan latar belakang diatas, maka penelitian ini bertujuan untuk menggambarkan penilaian mahasiswa mengenai kualitas jasa yang diberikan oleh universitas swasta di Kota Malang dan menggambarkan atribut kualitas jasa yang dinilai kurang oleh mahasiswa universitas swasta di Kota Malang.

\section{JASA}

\section{Pengertian Jasa}

Jasa adalah setiap tindakan atau perbuatan yang dapat ditawarkan oleh satu pihak yang pada dasarnya tidak berwujud dan tidak mengakibatkan kepemilikan apapun (Kotler, 2001). Jasa memiliki empat karakteristik yang membedakannya dengan produk barang (Tjiptono, 2000):

1. Intangibility yaitu jasa tidak dapat dilihat, dirasa, diraba, dicium, atau didengar sebelum dibeli.

2. Inseparability yaitu jasa biasanya lebih dahulu baru kemudian diproduksi dan dikonsumsi secara bersamaan.

3. Variability yaitu jasa bersifat sangat variable karena merupakan output yang sulit distandarisasi.

4. Perishability yaitu jasa adalah komoditas yang tidak tahan lama dan tidak dapat disimpan.

Menurut Wyckop (dalam Tjiptono, 2001) kualitas jasa adalah tingkat keunggulan yang diharapkan dan pengendalian atas tingkat keunggulan tersebut untuk memenuhi keinginan pelanggan. Terdapat dua faktor utama yang mempengaruhi kualitas jasa yaitu jasa yang diharapkan (expected service) dan jasa yang dipersepsikan (perceived service). Apabila jasa yang diterima atau dirasakan sesuai atau melebihi harapan maka kualitas jasa dipersepsikan baik dan sebaliknya. Hal ini berarti citra kualitas yang baik tidak berdasarkan persepsi penyedia jasa melainkan persepsi konsumen.

\section{Dimensi Kualitas Jasa}

Parasuraman dkk (Alma,2000) dalam penelitiannya menemukan lima dimensi kualitas jasa yang terdiri dari :

1. Tangibles (bukti fisik), yaitu penampilan sarana dan fasilitas fisik, perlengkapan dan peralatan, penampilan personil dan media komunikasi. 
2. Reliability (keandalan), yaitu kemampuan untuk memberikan jasa yang dijanjikan dengan segera, akurat, terpercaya, dan memuaskan.

3. Responsiveness (ketanggapan), yaitu kemampuan dan keinginan dari karyawan untuk membantu para pelanggan dan memberikan pelayanan dengan cepat dan tepat.

4. Assurance (jaminan), yaitu pengetahuan dan kemampuan karyawan dalam memberikan pelayanan sehingga dapat menimbulkan kepercayaan dan tidak menimbulkan karaguan pelanggan terhadap pelayanan.

5. Empathy (empati), yaitu adanya perhatian yang lebih bersifat pribadi kepada pelanggan, melakukan kontak, hubungan, dan komunikasi dengan pelanggan serta adanya upaya untuk memahami kebutuhan dan keinginan para pelanggan.

Zeithaml, Parasuraman, dan Berry (1990) merumuskan conceptual model of service quality dan menemukan beberapa kesenjangan (gap) yang menyebabkan kegagalan penyampaian jasa yaitu :

1. Gap antara harapan konsumen dan persepsi manajemen.

Kesenjangan ini terjadi karena pihak manajemen tidak memahami apa yang menjadi harapan pelanggan dengan baik.

2. Gap antara persepsi manajemen dan harapan konsumen dan spesifikasi kualitas jasa.

Kesenjangan ini terjadi karena adanya kesalahan persepsi manajemen dalam menterjemahkan harapan palanggan ke dalam bentuk standar kualitas pelayanan secara tepat.

3. Gap antara spesifikasi kualitas jasa dan penyampaian jasa.

Kesenjangan ini terjadi karena pihak manajemen tidak memahami apa yang menjadi harapan pelanggan dengan baik.

4. Gap antara penyampaian jasa dan komunikasi eksternal.

Kesenjangan ini terjadi karena pihak manajemen tidak memahami apa yang menjadi harapan pelanggan dengan baik.

5. Gap antara jasa yang dirasakan dan yang diharapkan.

Kesenjangan ini terjadi karena pihak manajemen tidak memahami apa yang menjadi harapan pelanggan dengan baik.

\section{KEPUASAN PELANGGAN}


Kepuasan pelanggan dapat tercipta dengan pemenuhan harapan pelanggan atas mutu produk atau jasa utama (Nangoi, 2002). Wilkie (dalam Tjiptono, 2000) mendefinisikan kepuasan pelanggan sebagai tanggapan emosional dan evaluasi terhadap pengalaman suatu produk atau jasa. Ketidakpuasan yang timbul dari rendahnya kinerja yang diterima dibandingkan dengan harapan dapat disebabkan oleh beberapa hal (Alma, 2000) yaitu :

1. Ketidaksesuaian harapan dengan kenyataan yang dialami

2. Layanan selama proses menikmati jasa tidak memuaskan

3. Perilaku personil kurang menyenangkan

4. Suasana dan kondisi fisik lingkungan yang tidak menunjang

5. Biaya terlalu tinggi karena jarak terlalu jauh, banyak waktu terbuang, dan harga yang terlalu tinggi

6. Promosi atau iklan tidak sesuai dengan kenyataan

\section{Perguruan Tinggi Bermutu}

Produk perguruan tinggi terdiri dari jasa pendidikan tinggi yang meliputi jasa kurikuler, jasa penelitian, jasa pengabdian pada masyarakat, jasa administrasi, dan jasa kurikuler. Tampubolon (2001) menyatakan terdapat lima usaha mendasar dalam kegiatan peningkatan mutu perguruan tinggi, yaitu :

1. Menciptakan dan menumbuhkan situasi M-M (win-win solution) yaitu kondisi di mana setiap orang memiliki kesempatan yang baik untuk mengembangkan diri.

2. Menumbuhkan motivasi intrinsik yaitu dorongan dari dalam (psikologis) diri seseorang untuk melakukan sesuatu yang baik.

3. Peningkatan mutu berkelanjutan

4. Menumbuhkan persaingan dalam konteks kerjasama

5. Mencegah lebih baik daripada memperbaiki, kelemahan atau kesalahan dapat dicegah apabila sistem dan semua proses dikendalikan sejak awal.

\section{METODE}

\section{Jenis Penelitian}

Sesuai dengan tujuan penelitian maka penelitian ini termasuk jenis penelitian deskriptif yaitu penelitian yang bertujuan untuk memberikan gambaran secara sistematis, faktual, dan akurat mengenai fenomena yang diselidiki (Arikunto, 1997). 


\section{Populasi dan Sampel}

Populasi penelitian ini adalah seluruh mahasiswa fakultas ekonomi dari sepuluh universitas swasta yang ada di kota Malang. Pengambilan sampel dilakukan dengan teknik purposive dan accidental sampling. Sampel sebanyak 100 orang diukur dengan menggunakan rumus Slovin (Umar, 2002) yaitu :

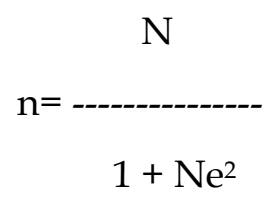

Di mana :

$\mathrm{n}=$ ukuran sampel

$\mathrm{N}=$ jumlah populasi

$\mathrm{e}=$ prosentase kelonggaran ketelitian yang ditoleransi $(10 \%)$

Berdasarkan rumus di atas deketahui jumlah sampel sebesar 99,48 yang dibulatkan menjadi 100 responden. Responden dalam penelitian ini adalah mahasiswa fakultas ekonomi yang minimal sudah semester 5. Data yang digunakan dalam penelitian ini adalah data primer dan sekunder. Data primer diperoleh dari kuisioner dengan 22 item pertanyaan.

\section{Definisi Operasional}

Dimensi kualitas jasa ada lima yaitu :

1. Tangibles (Ta) yang dijabarkan ke dalam empat atribut kualitas jasa yaitu kelengkapan fasilitas kemahasiswaan (Ta1), kelengkapan fasilitas pendidikan (Ta2), kebersihan lingkungan (Ta3), dan peralatan dalam proses belajar mengajar (Ta4).

2. Reliability (Rel) yang dijabarkan ke dalam lima atribut kualitas jasa yaitu keakuratan dosen dalam memberikan nilai (Rel1), keakuratan pencatatan laporan akademik (Rel2), ketepatan jam mengajar (Rel3), kesiapan dosen dalam memberikan perkuliahan (Rel4), dan peran karyawan dalam menjamin kelancaran perkulihan (Rel5).

3. Responsiveness (Res) yang dijabarkan ke dalam empat atribut kualitas jasa yaitu ketanggapan dosen dan karyawan terhadap permasalahan mahasiswa (Res1), kesiapan dan kesediaan dosen dan karyawan dalam membantu mahasiswa (Res2), kemauan dosen dan karyawan dalam mendengarkan sumbang saran dari mahasiswa (Res3), dan kejelasan informasi penyampaian jasa (Res4). 
4. Assurance (As) yang dijabarkan ke dalam empat atribut kualitas jasa yaitu kemampuan dan pengetahuan dosen dalam memberikan kuliah (As1), perilaku dosen di depan kelas (As2), pengalaman mengajar dosen (As3), dan kualifikasi akademik dosen (As4).

5. Empathy (Em) yang dijabarkan ke dalam lima atribut kualitas jasa yaitu kemudahan untuk menemui dosen (Em1), pengertian dan pemahaman dosen terhadap kebutuhan mahasiswa (Em2), perhatian dosen terhadap mahasiswa (Em3), perhatian karyawan terhadap mahasiswa (Em4), dan dosen dan karyawan melayani mahasiswa dengan baik dan ramah (Em5).

Kepuasan mahasiswa adalah tanggapan mahasiswa mengenai tingkat kepuasan keseluruhan berdasarkan pengalamannya. Indikator kepuasan terdiri dari puas atas kualitas dosen, jasa karyawan, administrasi umum dan akademik, dan ketersediaan sarana fisik atau material.

\section{Analisis Data}

Analisis data dalam penelitian ini adalah analisis deskriptif dengan menggunakan Importance-Performance Analysis yang dikemukakan oleh Martila dan James (Supranto, 1997), untuk menemukan tingkat kesesuaian antara tingkat kepentingan (harapan) dengan tingkat pelaksanaan (kinerja) jasa universitas swasta di kota Malang. Rumus tingkat kesesuaian yang digunakan adalah :

$$
\text { Tki = ------- } \times 100 \%
$$

$\mathrm{Hi}$

Di mana :

Tki $=$ Tingkat kesesuaian

$\mathrm{Ki}=$ Skor penilaian kinerja / pelaksanaan

$\mathrm{Hi}=$ Skor penilaian harapan / tingkat kepentingan

Analisis ini dilanjutkan dengan melakukan pemetaan ke dalam diagram kartesius untuk melihat posisi masing-masing atribut kualitas. Selanjutnya dapat ditafsirkan atribut-atribut mana yang perlu dijadikan prioritas utama, dipertahankan, prioritas rendah, dan yang berlebihan berdasarkan kuadran-kuadran yang ada dalam diagram. Adapun diagram kartesius yang dimaksud adalah sebagai berikut: 


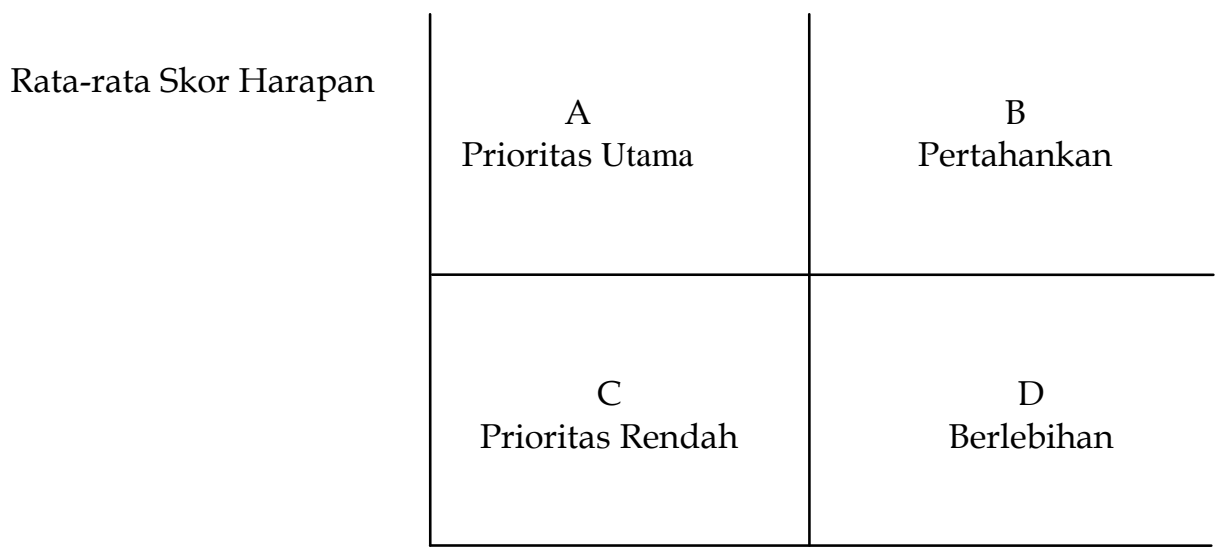

Rata-rata Skor Kinerja

Interpretasi dari setiap kuadran di atas adalah :

A. Prioritas utama, penyedia jasa harus memfokuskan diri pada kuadran ini karena atribut yang berada di sini diharapkan ada oleh pelanggan tetapi kinerja yang dipersepsikan kurang. Beberapa perubahan harus dilakukan untuk memperkecil gap yang timbul.

B. Pertahankan, atribut yang ada di dalam kuadran ini diharapkan oleh pelanggan dan kinerja dipandang sudah bagus sehingga harus dipertahankan.

C. Prioritas rendah, pelanggan tidak mengharapkan atribut yang ada di kuadran ini dan mempersepsikan kinerja yang diberikan kurang bagus. Penyedia jasa tidak perlu memaksakan untuk meningkatkan kualitas jasa dari atribut yang ada dalam kuadran ini.

D. Berlebihan, atribut dalam kuadran ini tidak terlalu diharapkan oleh pelanggan namun memiliki kinerja yang bagus. Untuk sementara tidak ada strategi yang perlu diambil namun penyedia jasa harus memantau untuk mengantisipasi bila suatu saat atributatribut ini semakin diharapkan.

\section{PEMBAHASAN}

Data yang digunakan dalam penelitian ini terbagi menjadi dua yaitu data yang berkaitan dengan persepsi responden terhadap kualitas jasa yang diharapkan berdasar tingkat kepentingan dan data yang berhubungan dengan persepsi responden terhadap kualitas jasa yang dirasakan. Analisis tingkat kepentingan dan kinerja (Importance - Performance Analysis) dilakukan dengan membandingkan jumlah skor jawaban masing-masing pertanyaan untuk 
mendapatkan prosentase tingkat kesesuaian antara kinerja dan harapan. Berdasarkan prosentase tingkat kesesuaian tersebut dapat dihitung rata-rata tingkat kesesuaian dari itemitem pertanyaan yang menggambarkan bagaimana kualitas jasa universitas swasta di Kota Malang.

Pada saat melakukan pemetaan ke dalam diagram kartesius, skor jawaban dari 100 responden masing-masing item dihitung rata-ratanya. Jumlah rata-rata skor 22 item ini dihitung lagi rata-ratanya. Pada diagram kartesius, rata-rata dari rata-rata untuk skor kualitas jasa yang diharapkan berada pada sumbu vertikal yang diberi tanda $\mathrm{H}$ dan skor rata-rata dari rata-rata skor kualitas jasa yang dirasakan berada pada sumbu horizontal dan diberi tanda $\mathrm{K}$.

Hasil perhitungan tingkat kesesuaian yang dinyatakan dalam bentuk prosentase dapat dilihat pada tabel berikut :

Tabel 1. Tingkat Kesesuaian antara Kualitas yang Diharapkan dan Kualitas yang Dirasakan

\begin{tabular}{|c|c|c|c|}
\hline Atribut & Skor kinerja (Ki) & $\begin{array}{c}\text { Skor harapan } \\
(\mathrm{Hi})\end{array}$ & $\begin{array}{c}\text { Kesesuaian } \\
(\mathrm{Tki})(\%)\end{array}$ \\
\hline Ta1 & 377 & 461 & 81,78 \\
\hline Ta2 & 387 & 411 & 94,16 \\
\hline Ta3 & 359 & 417 & 86,10 \\
\hline Ta4 & 379 & 431 & 87,93 \\
\hline Rel1 & 337 & 401 & 84,04 \\
\hline Rel2 & 368 & 442 & 83,26 \\
\hline Rel3 & 348 & 359 & 96,94 \\
\hline Rel4 & 365 & 425 & 85,88 \\
\hline Rel5 & 347 & 363 & 95,59 \\
\hline Res1 & 323 & 365 & 88,49 \\
\hline Res2 & 325 & 399 & 81,45 \\
\hline Res3 & 334 & 414 & 80,68 \\
\hline Res4 & 361 & 420 & 85,95 \\
\hline As1 & 383 & 412 & 92,96 \\
\hline As2 & 401 & 385 & 104,16 \\
\hline As3 & 379 & 369 & 102,71 \\
\hline As4 & 382 & 389 & 98,20 \\
\hline Em1 & 338 & 426 & 79,34 \\
\hline Em2 & 326 & 388 & 84,02 \\
\hline Em3 & 345 & 346 & 99,71 \\
\hline Em4 & 299 & 353 & 84,70 \\
\hline Em5 & 346 & 422 & 81,99 \\
\hline & Rata-rata tingkat kesesuaian & 89,09 \\
\hline
\end{tabular}

Sumber : Data primer diolah 
Dari tabel di atas, diperoleh angka rata-rata tingkat kesesuaian sebesar 89,09\%. Hal ini mengindikasikan bahwa berdasarkan penilaian mahasiswa ternyata kinerja kualitas jasa universitas swasta di Kota Malang masih berada di bawah harapan mereka karena terdapat kesenjangan sebesar 10,91\%. Menurut Kotler (2001) jika kualitas yang diterima lebih rendah daripada yang diharapkan maka kualitas dipersepsikan buruk. Jika hal ini dihubungkan dengan kepuasan pelanggan berarti kualitas jasa universitas swasta di Kota Malang dirasa belum memuaskan karena kinerja berada di bawah harapan. Hasil penelitian ini mendukung hasil penelitian Nas (2001) yang menyatakan bahwa terdapat kesenjangan antara kualitas jasa yang diharapkan dengan yang diterima mahasiswa PTS di Banjarmasin sebesar 13,90\% dan Shalehuddin (1999) walaupun dengan dimensi kualitas jasa yang berbeda.

Namun demikian ternyata ada dua atribut kualitas jasa yang dianggap sudah baik yaitu atribut perilaku dosen di depan kelas (berpakaian rapi) dan pengalaman mengajar dosen (tiga tahun atau lebih) yang masing-masing tingkat kesesuaiannya 104,16\% dan 102,71\%. Hasil ini berbeda dengan hasil penelitian Nas (2001) karena atribut kualitas jasa yang dirasakan sudah baik adalah atribut proporsi dosen-mahasiswa dan silabi perkuliahan. Sedangkan 20 atribut yang lain mempunyai tingkat kesesuaian di bawah 100\%.

Untuk melihat posisi dari masing-masing atribut kualitas jasa maka skor tersebut dipetakan ke dalam disgram kartesius. Sebelumya dibuat tabel sebagai berikut :

Tabel 2. perhitungan rata-rata skor penilaian kinerja dan harapan atribut kualitas jasa

\begin{tabular}{|c|c|c|c|c|}
\hline Atribut & Skor kinerja (Ki) & $\begin{array}{c}\text { Skor harapan } \\
(\mathrm{Hi})\end{array}$ & $\begin{array}{c}\text { Rata-rata Ki } \\
(\mathrm{K})\end{array}$ & $\begin{array}{c}\text { Rata-rata Hi } \\
(\mathrm{H})\end{array}$ \\
\hline Ta1 & 377 & 461 & 3,77 & 4,61 \\
\hline Ta2 & 387 & 411 & 3,87 & 4,11 \\
\hline Ta3 & 359 & 417 & 3,59 & 4,17 \\
\hline Ta4 & 379 & 431 & 3,79 & 4,31 \\
\hline Re11 & 337 & 401 & 3,37 & 4,01 \\
\hline Re12 & 368 & 442 & 3,68 & 4,42 \\
\hline Re13 & 348 & 359 & 3,48 & 3,59 \\
\hline Re14 & 365 & 425 & 3,65 & 4,25 \\
\hline Re15 & 347 & 363 & 3,47 & 3,63 \\
\hline Res1 & 323 & 365 & 3,23 & 3,65 \\
\hline Res2 & 325 & 399 & 3,25 & 3,99 \\
\hline Res3 & 334 & 414 & 3,34 & 4,14 \\
\hline Res4 & 361 & 420 & 3,61 & 4,20 \\
\hline As1 & 383 & 412 & 3,83 & 4,12 \\
\hline As2 & 401 & 385 & 4,01 & 3,85 \\
\hline As3 & 379 & 369 & 3,79 & 3,69 \\
\hline
\end{tabular}




\begin{tabular}{|c|c|c|c|c|}
\hline As4 & 382 & 389 & 3,82 & 3,89 \\
\hline Em1 & 338 & 426 & 3,38 & 4,26 \\
\hline Em2 & 326 & 388 & 3,26 & 3,88 \\
\hline Em3 & 345 & 346 & 3,45 & 3,46 \\
\hline Em4 & 299 & 353 & 2,99 & 3,53 \\
\hline Em5 & 346 & 3,46 & 4,22 \\
\hline \multicolumn{2}{|r}{} \\
\hline
\end{tabular}

Sumber : Data primer diolah

Nilai rata-rata yang terdapat pada tabel di atas dijadikan titik tolak dalam membuat diagram kartesius sehingga dapat diketahui letak masing-masing atribut kualitas jasa pada setiap kuadran.

Gambar di bawah ini menjelaskan hal tersebut.

Rata-rata skor harapan

\begin{tabular}{||c|c} 
A & B \\
Prioritas utama & Pertahankan \\
Rel1 & Ta1 \\
Res3 & Ta2 \\
Em1 & Ta3 \\
Em5 & Ta4 \\
& Rel2 \\
& Rel4 \\
& Res4 \\
& As1 \\
Res2 & D \\
C & Berlebihan \\
Prioritas rendah & As2 \\
Rel3 & As.3 \\
Rel.5 & As4 \\
Res.1 & \\
Em2 & \\
Em3 & \\
Em4 &
\end{tabular}

Berdasarkan diagram kartesius di atas dapat dijelaskan bahwa :

Kuadran A, empat atribut berada di dalam kuadran ini yaitu Rel1 (keakuratan dosen dalam memberikan nilai), Res3 (kemauan dosen dan karyawan dalam mendengarkan sumbang Created with 
saran dari mahasiswa), Em1 (kemudahan untuk menemui dosen), dan Em5 (dosen dan karyawan melayani mahasiswa dengan baik). Keempat atribut tersebut memiliki tingkat harapan yang tinggi di atas rata-rata tetapi nilai kinerja yang dirasakan masih di bawah nilai rata-rata. Pengelola universitas swasta di Kota Malang harus memfokuskan perhatian pada kuadran ini karena atribut yang berada di sini diharapkan ada oleh mahasiswa tetapi kinerja dirasa kurang.

Kuadran B, delapan atribut berada di kuadran ini yaitu Ta1 (kelengkapan fasilitas kemahasiswaan), Ta2 (kelengkapan fasilitas pendidikan), Ta3 (kebersihan lingkungan), Ta4 (peralatan dalam proses belajar mengajar), X2.2 (keakuratan pencatatan laporan akademik), X2.4 (kesiapan dosen dalam memberikan perkuliahan), Res4 (kejelasan informasi penyampaian jasa), dan As1 (kemampuan dan pengetahuan dosen dalam memberikan kuliah). Kedelapan atribut tersebut merupakan kekuatan bagi universitas swasta di Kota Malang sehingga harus dipertahankan kinerjanya.

Kuadran C, enam atribut berada di kuadran ini yang terdiri dari Rel3 (ketepatan jam mengajar), Rel5 (peran karyawan dalam menjamin kelancaran perkulihan), Res1 (ketanggapan dosen dan karyawan terhadap permasalahan mahasiswa), Em2 (pengertian dan pemahaman dosen terhadap kebutuhan mahasiswa), Em3 (perhatian dosen terhadap mahasiswa), Em4 (perhatian karyawan terhadap mahasiswa). Keenam atribut di atas mengindikasikan bahwa mahasiswa memiliki tingkat harapan di bawah tingkat harapan rata-rata dan kinerja yang dirasakan juga di bawah kinerja rata-rata. Hasil penelitian ini menunjukkan bahwa indikator Rel3, Rel5, dan Em3 meskipun memiliki nilai harapan di bawah harapan rata-rata namun mempunyai kinerja mendekati nilai kinerja rata-rata. Sedangkan indikator Res1, Em2, dan Em4 meskipun memiliki tingkat kinerja di bawah kinerja rata-rata namun tingkat harapannya cenderung mendekati rata-rata sehingga ketiga atribut tersebut dapat ditempatkan pada kuadran A untuk lebih diperhatikan dan pada akhirnya akan berubah menjadi kekuatan.

Kuadran D, tiga atribut berada di kuadran ini yaitu As2 (perilaku dosen di depan kelas), As3 (pengalaman mengajar dosen), dan As4 (kualifikasi akademik dosen). Hal ini berarti ketiga atribut tersebut dirasakan berlebihan oleh mahasiswa.

Atribut Res2 yaitu kesiapan dan kesediaan dosen dan karyawan dalam membantu mahasiswa mempunyai tingkat kinerja lebih rendah dari nilai kinerja rata-rata tetapi dengan tingkat harapan yang sama dengan tingkat harapan rata-rata. Hal ini menunjukkan bahwa 
atribut Res2 dapat ditempatkan pada kuadran A untuk mendapatkan perhatian yang lebih dan dilakukan perbaikan-perbaikan agar dapat bergeser ke kuadran B sehingga menjadi kekuatan bagi universitas swasta di Kota Malang.

Kesenjangan tertinggi terjadi pada salah satu atribut empathy yaitu Em1 (kemudahan untuk menemui dosen baik di rumah atau di kampus). Hasil ini mendukung hasil penelitian Shalehuddin (1999) namun berbeda dengan hasil penelitian Nas (2001) yang menunjukkan bahwa kesenjangan tertinggi terjadi pada salah satu indikator variabel recovery yaitu kondisi perpustakaan.

\section{KESIMPULAN DAN SARAN}

\section{Kesimpulan}

1. Penilaian mahasiswa mengenai kualitas jasa yang diberikan oleh universitas swasta di kota Malang adalah kinerja kualitas jasa masih berada di bawah kualitas jasa yang diharapkan karena terdapat kesenjangan sebesar 10,91\% sehingga dirasakan belum memuaskan oleh mahasiswa.

2. Terdapat empat atribut kualitas jasa yang dinilai kurang oleh mahasiswa universitas swasta di Kota Malang yaitu atribut-atribut yang berada di kuadran A yang terdiri dari Rel1 (keakuratan dosen dalam memberikan nilai), Res3 (kemauan dosen dan karyawan dalam mendengarkan sumbang saran dari mahasiswa), Em1 (kemudahan untuk menemui dosen), dan Em5 (dosen dan karyawan melayani mahasiswa dengan baik).

\section{Saran}

1. Pihak pengelola universitas swasta harus memberikan prioritas utama pada empat atribut kualitas jasa yang menurut mahasiswa masih belum dilaksanakan dengan baik padahal sangat diperlukan oleh mahasiswa yaitu keakuratan dosen dalam memberikan nilai, kemauan dosen dan karyawan dalam mendengarkan sumbang saran dari mahasiswa, kemudahan untuk menemui dosen, dan dosen dan karyawan melayani mahasiswa dengan baik.

2. Bagi penelitian selanjutnya perlu menambahkan atribut-atribut kualitas jasa yang lain dan dapat meneliti kualitas jasa pada masing-masing universitas swasta semacam studi kasus. Selain itu juga dapat meneliti kesenjangan-kesenjangan (gap-gap) lain yang tidak tercakup dalam penelitian ini. 


\section{DAFTAR PUSTAKA}

Alma, Buchari. 2000. Manajemen Pemasaran dan Pemasaran Jasa. Bandung: CV Alfabeta.

Arikunto, Suharsimi. 1997. Prosedur Penelitian Suatu Pendekatan Praktek. Jakarta: PT. Rineka Cipta.

Direktori PTS KOPERTIS WIL. VII Jawa Timur. 2003. Diterbitkan oleh KOPERTIS WIL. VII Jawa Timur.

Gaspers, Vincent. 1997. Manajemen Kualitas dalam Industri Jasa. Jakarta: PT. Gramedia Pustaka Utama.

Handriana. T. 1998. Analisis Perbedaan Harapan Kualitas Pelayanan pada Lembaga Pendidikan Tinggi di Surabaya. Tesis. Universitas Gajah Mada. Yogyakarta.

Kotler, Philip. dan A.B. Susanto. 2000. Manajemen Pemasaran di Indonesia. Jakarta: Penerbit Salemba Empat.

Kotler, Philip. dan Gary Amstrong. 2001. Prinsip-prinsip Pemasaran. Alihbahasa Damos Sihombing. Jakarta: Erlangga.

Nas, Syamsah. 2001. Kualitas Jasa Kependidikan dan Pengaruhnya terhadap Kepuasan Mahasiswa PTS di Banjarmasin. Tesis. Universitas Brawijaya. Malang.

Nangoi, Ronald. 2002. Meningkatkan Customer Service. Manajemen No 171 November 2002.

Parasuraman, A., Valerie A. Zeithaml, Leonard L. Berry. 1988. SERVQUAL : Multiple Item Scale for Measuring Consumer Perception of Service Quality. Journal of Retailing, Vol 64, p. $12-40$.

1990. Delivering Quality Service : Balancing customer Perceptions and Expectations. New York: The Free Press.

Sabihaini. 2002. Analisis Konsekuensi Keperilakuan Kualitas Layanan : Suatu Penelitian Empiris. Manajemen Usahawan, No. 02/TH. XXXI Februari 2002.

Shalehuddin. 1999. Pengaruh Kualitas Jasa (Service Quality) terhadap Kepuasan dan Loyalitas Pelanggan. Tesis. Universitas Brawijaya. Malang.

Supranto, J. 1997. Pengukuran Tingkat Kepuasan Pelanggan untuk Meningkatkan Pangsa Pasar. Jakarta: Penerbit Rineka Cipta.

Tampubolon, Daulat P. 2001. Perguruan Tinggi Bermutu. Jakarta: Penerbit PT. Gramedia Pustaka Utama.

Tjiptono, Fandy. 2000. Manajemen Jasa. Edisi Kedua. Penerbit Andi. Yogyakarta.

-------. 2001. Prinsip-Prinsip Total Quality Service. Yogyakarta: Penerbit Andi.

Umar, Husein. 2002. Metodologi Penelitian-Aplikasi dalam Pemasaran. Jakarta: Penerbit PT. Gramedia Pustaka Utama. 